\title{
Principals' Attitudes towards International Exchange Activities in the Context of Taiwan
}

\author{
Wei-Ting Huang ${ }^{1}$ \\ ${ }^{1}$ The University of Edinburgh, UK \\ Correspondence: Wei-Ting Huang, The University of Edinburgh, UK. E-mail: pooh04193324@gmail.com
}

Received: March 20, 2018

Accepted: May 4, 2018

Online Published: May 15, 2018

doi:10.5539/ijbm.v13n6p97

URL: https://doi.org/10.5539/ijbm.v13n6p97

\begin{abstract}
Globalization has rendered frequent and convenient cross-country interaction and thus led to the emergence of international education. Drawing on an international education white paper specifically designed for students at primary and secondary schools in Taiwan, this study explores attitudes of principals towards the advantages, disadvantages and implementation challenges of the white paper. A self-developed questionnaire was utilized and distributed to 120 principals in Taiwan with a return rate of approximately $74 \%$. The results indicate that while many benefits brought by international exchange activities have been recognized, some unexpected outcomes have also been identified as possible hindrances for students' learning and development. Extra exchange activities may increase students' pressure for learning; instructors' subjective international outlook may cause misleading international cognition, and focusing on powerful countries may lead to a narrowed international outlook. In addition, some implementation challenges explored in this research also manifest the existing administrative problems embedded in school systems such as lack of qualified teaching staff and administrators and lack of mutual cooperation among faculty. These findings can be referenced by Taiwanese policy makers to improve or revamp the white paper in the future.
\end{abstract}

Keywords: globalization, international education, international exchange activities, internationalist, globalist

\section{Introduction}

With the advance of modern transportation and electronic communication devices, cross-border interaction has become exponentially convenient and frequent as geographical distance has gradually ceased to be an obstacle (Kotz, 2002). The blurring boundaries between countries have stimulated global flows of human capital, economics, politics, knowledge, fashion and culture (Stier, 2003). Under such a globalised society, an academic field has emerged - international education.

While many practitioners recognize that international education helps cultivate a global mind-set and intercultural competences for future generations, opponents consider this form of education an instrument for affluent groups to strive forth in the ever-burgeoning globalised society (Joris, 2006). Nevertheless, the idea of internationalising education systems has been identified by numerous academics as a fundamental step for succeeding generations to function in the globalised world (Yang, 2002; Qiang, 2003; Altbach and Knight, 2007; Kreber, 2009).

Despite existing debates, Taiwan remains in need of international education considering its limited opportunities for international activities and cultural exchanges (Chen, 2015). To cultivate an international mind-set and competencies in human capital, the government of Taiwan has recognised the need to implement educational reform targeting young students for international education as the up-coming globalised generation. Consequently, the government published a white paper on international education for primary and secondary schools in 2012, declaring a determination to establish a foundation of international education (ibid.); including, the promotion of internationalised curriculum, additional training for qualified teachers, implementing international exchange activities and an internationalisation of learning environments.

Informed by a thorough review of previous research on this policy, while the evaluation in its practice has been widely discussed, attitudes of individuals among the senior hierarchy of schools towards the effects of this policy have been underestimated, especially the perceived negative effects. In addition, although some challenges for the implementation are raised in the white paper, there is also no research focusing on exploring individuals' 
attitudes towards these challenges. With the White Paper (2012) in mind, this study focuses on 'international exchange activities' as this aspect has been the most widely implemented by schools in recent years (Huang, 2015). To explore this aspect three research questions have emerged:

1. What are the attitudes of Taiwanese principals towards the positive effects of international exchange activities for students of primary and secondary education?

2. What are the attitudes of Taiwanese principals towards the negative effects of international exchange activities for students of primary and secondary education?

3. What are the attitudes of Taiwanese principals towards the challenges to undertake international exchange activities for students of primary and secondary education?

4. Do the attitudes of these principals differ significantly by their gender, educational backgrounds, type of schools and level of schools?

\section{Literature Review}

\subsection{Development of International Education}

The establishment of the Spring Grove School in London (1866) and the International School of Geneva (1924) are deemed as examples of the founders of international education (Hayden and Thompson, 2000; Hill, 2001). According to Sylvester (2002), the Spring Grove School in London was founded based on curriculums that explicitly espoused the ideals of internationalism, which has strived to provide students with opportunities to participate in a programme that instils greater fraternity, more tolerance and world peace in students. While for the International School of Geneva, the primary task is to assist students in securing employment in the League of Nations (International School of Geneva, 2015). In addition, it is claimed that there was a need to cater for students with diverse socio-cultural backgrounds and prepare them for higher education (ibid.). This context represents a perspective that lays emphasis on the development of individual competency. However, the ideology of international education was not fostered until the second world war when there was a commitment to avoid further conflict by means of international education (Goodings and Lauwery, 1964). In 1950, Kurt Hahn collaborated with some commandants and founded the Atlantic College. At that time, with an aim to eliminate national prejudice, young people aged 16 to 18 from different national backgrounds were gathered together to study and learn about values and beliefs from other cultures.

In the mid-1970s, the swift progression of globalisation stimulated significant growth of international schools (Bunnell, 2005). According to Wylie (2008), the market for international education has developed tremendously over the past few decades with countries increasingly starting to establish policies and strategies to implement international education and even promote their schools overseas. As the global trade of goods continues to develop, there is a growing number of emigrant workers seeking international schools for their children (Hayden and Thompson, 2013). However, the lack of a unified international programme for students had presented direct challenges for teachers coping with students with mixed backgrounds; specifically, difficulties in preparing learning materials suitable for culturally diverse students. To address such problems, many international schools have highlighted the need to establish a mutual international programme. This has helped in the creation of the International Baccalaureate (IB) programme. By deliberately gathering students aged 16 to 18 to study and live together, this non-profit educational foundation, albeit in highly contested position, helps to engage others in critical thinking through the lens of various international perspectives (Hayden, 2006). Despite its original aim to provide an internationally standardised education system, it does not escape opposition and criticism. As Wright, Lee and Tang (2016) point out, IB schools focus on cultivating groups of highly competitive students for entering elite higher education institutions. In addition, other critics assert that students' minds may be shaped towards globalism; that is, if students fail to submit to a 'globalist' way of thinking for the examinations, their chances in obtaining adequately high scores to enter elite schools is compromised (Mathews, 2001). This long-lasting tension also exerts an influence on the approach to define international education, which is discussed below.

\subsection{Defining International Education}

In the evolutionary history of educational research, international education is viewed as a more recent phenomenon with preliminary study first appearing in the early 1960s (House, 2015). Consequently, there is a general recognition that international education lacks a unanimous definition (Crossley and Watson, 2003; Hunter and Godbey 2006; Dolby and Rahman, 2008). Currently, definitions of international education differ from broad to specific descriptions. Hayden and Thompson $(1995$, p.17) state that "international education is a dynamic concept that involves a journey or movement of people, minds, or ideas across political and cultural 
frontiers." This statement is considered by Hansen (2002) as the most appropriate definition that encapsulates the many aspects that people may experience. Others, like Husen and Postlethwaite (1995) assert that international education refers to all educational efforts that intend to foster an international-oriented awareness and mind-set. Similarly, Watson (1999) argues that these efforts should be organised to gather students, practitioners, policy-makers and academics around the globe to exchange perspectives towards international affairs. Hall (1990) provided a more specific description in terms of the locations that international education takes place. He stated that international education not only occurs abroad through the provision of overseas programmes or educational visits to other countries, it can also happen within domestic environments through integrating culturally divergent content into course curriculums. Emert and Pearson (2007) summarise and synthesise these statements, claiming that international education is composed of educational efforts that inculcate internationally-oriented themes, outlooks and experiences within and across countries to raise awareness and a deeper understanding of our diverse world. However, from a less positive perspective, Sung and Park (2013) examined a national curriculum in South Korea and found that equipping students with global visions has been appropriated as a key factor for the design of the curriculum. In the curriculum they examined, they found that international education in this context is in fact regarded as a tool for South Korea to survive and strive towards the globalised era. In their definition, international education is primarily an instrument of the authorities to restore national pride. Little consideration has been given to the fundamental role of education in cultivating students to become individuals with responsibilities for global affairs. They assert that this economically-centred perspective of international education would ultimately obstruct students from professionally considering social, environmental and other dimensions of globalisation. This argument has been supported by a previous research of Roman (2003), which concludes that international education is business-focused and a process of taking advantage of the inequalities generated from Western dominance. Nevertheless, Young (2010) holds a contradictory perception towards these arguments in his review of various conceptualisations of the term. It is argued that international education concerns universal welfare and the interconnected relationships between humans and environmental systems, rather than the narrower concerns with national economic interest and domestic pride.

\subsection{Research on Attitudes towards International Education}

As international education has exerted not only positive but negative effects, it is crucial to identify a wide range of stances or thoughts in its outcomes from different stakeholders. Some findings from previous research are of particular relevance to my study in terms of positive and negative attitudes towards this kind of education, which are now outlined.

\subsubsection{Positive Attitudes}

In a study of the correlation between international education and students' employability in Australia by Crossman and Clarke (2009), it was concluded that international education helps increase students' opportunities for transnational employment. Students are cultivated with competencies that global recruiters require, such as problem-solving and critical thinking in diverse cultural settings. Crossman and Clarke (2009) uphold this assertion qualitatively by synthesising perceptions gained in interviews involving three stakeholders (employers, academics and students). Here, a shared perception was found in that possessing international experience or mind-set does enhance critical analysis ability, sociability with a learned respect towards other cultures, which are crucial elements required to survive in a globalised labour market. This argument is supported by Thomas and Inkson's (2004) research on cultural intelligence, which stresses the importance of abilities to effectively and inclusively work with people from diverse cultural backdrops, especially in the era of globalisation.

Carley, Cheurprakobkit and Paracka (2006) conducted a survey with faculty from the Kennesaw State University in America. In this survey, the faculty's attitudes towards benefits of international learning were examined. The findings indicate that international education renders students more appreciative and more concerned about other cultures and global affairs. As informed by Leach's (1969) conceptualisation of internationalism, an exchange of students between countries can serve as a gateway to foster international cooperation. On the other hand, students also develop a national identity and understanding of their respective cultures. This is supported in Umar's exploration of the definition of international education (2013). She claims that students may make keen observations about their own nation under their sense of identity as 'foreigners' in foreign country, and thus foster the sense of belonging to their home countries.

Parmenter et al.'s, (2000) research in national identity development of elementary school children in Japan, Macau and Hong Kong concurs with Umar (2013). They claim that school has a responsibility to provide students with opportunities to construct, not only global or regional identities, but also a national identity. Therefore, if these various identities are recognised, the concept of multiple identities would not be conflictual, 
despite globalisation being regarded as a threat to national identity (Hobsbawm, 1996).

In terms of whether international education is truly promoted, especially in international schools, Hayden, Thompson and Williams (2003) conducted a large-scale survey to gather views of students from 72 different nationalities by six international programmes in the UK. The results show that the questions relating to language speaking ability were scored highly by all sub-groups. The justifications for this result were manifold, but the respondents all evidently attached much weight to issues relating to language, indicating that international education is considered to enhance intercultural communication skills.

While much of the literature has explored positive sides of international education, a review of its potential negative influences can help understand the comprehensive phenomenon. The following section provides a review of recent research exploring negative attitudes towards international education.

\subsubsection{Negative Attitudes}

A recent study that adopting surveys and focus groups has identified the attitudes of 29 teachers toward international education in an international school in Thailand (Deveney, 2007). Although a strong consensus exists among the participants, that the only way to develop diverse cultural responsiveness is 'on the job' rather than taking extra workshops on 'how to be an international-minded teacher', it was recognised that teachers' values can dictate the way in which messages are interpreted and conveyed to students. As Boysen (2012) has stated, teachers are human beings that they are not immune from bias. Therefore, teachers who bring their misconceptions of international issues may misguide their students. Deveney (2007) concluded that if teachers can recognise the importance of learning from one another and actively participate in forums in which information is shared and teacher collaboration is supported, misleading international recognition caused by instructors' subjective international outlook would be avoided. In another study, carried out by Volet and Ang (1998), eleven semi-structured focus groups were utilised to research the attitudes of 17 Australian students and 23 international students who were invited to complete two academic assignments in culturally mixed groups. The findings indicate that both the Australian and international students were inclined to complete the assignments with others that shared a similar national identity, and it was concluded that the lack of interaction between domestic students and international students should not be underestimated. Volet and Ang (1998) also recognised that the difficulties in adapting to a foreign culture, not only cause feelings of isolation, but also impede individual students from achieving satisfactory learning outcomes. The difficulties in interaction between domestic and international students are maintained in a further report by Yefanova, Baird and Montgomery (2015) in which a series of focus groups and individual interviews elicited the views of 121 domestic and international students and 47 faculty members at the University of Minnesota. Here, the majority of students and faculty surveyed were found to encounter difficulties in cross-national interactions due to language and cultural barriers. Other factors such as "bias, prejudice and pressure to succeed in academics" also cause ineffective interaction among students and teachers (ibid., p.3). The researchers suggest that a purposefully organised curriculum encouraging collaborative learning is required to foster effective interactions. Regarding the issue of adaptation encountered by students, Wu, Garza and Guzman (2015) conducted qualitative research with 10 international students in America. The data reveal that participants devoted most of their time discussing academic related challenges during interviews. Most students admitted that the excessive pressure resulting from physical, psychological, cultural and social relationships has impaired their will to learn. Wu, Garza and Guzman conclude by suggesting that the challenges faced by international students should be addressed and more support should be provided to enhance their learning outcomes.

\subsection{The Context of Taiwan}

Taiwan is a country that has long strived to obtain international recognition. Since its loss of seat with the United Nations in 1971, Taiwan's international activities and cultural exchanges with other countries have been restricted. Additionally, as encircled by sea, the economic development of Taiwan is heavily dependent on international trade. With this background, to avoid being marginalised, broadening a global outlook and fostering international competitiveness of human capital, is fundamental to Taiwan's continued growth. Motivated by these purposes, the government has embarked on educational reform targeting students of primary and secondary education. In 2012, an official document named A White Paper on International Education for Primary and Secondary Schools was released. Students are anticipated to raise their awareness of how Taiwanese people are connected and influenced by international networks; they are also expected to become more concerned about international affairs and respecting people of diverse cultural backgrounds.

In this policy, international education is divided into four major aspects: Curriculum Integration, International Exchange Activities, Administrator/Teacher Professional Development and School Internationalisation. Given 
the differentiation in individual schools (i.e., urban-rural gap, wealth and poverty gap), a School-based International Education Project has been adopted. Firstly, administrative faculty conduct a SWOT analysis to evaluate their school and select one to four aspects of international education to focus upon. Afterwards, proposals must be submitted to the Ministry of Education for additional subsidy support. However, this policy is not compulsory for every primary and secondary school; the decision to follow up the policy is afforded to individual schools.

Having examined relevant research on this policy, most of the studies focus on an evaluation of its effectiveness. Little exploration has been carried out on the attitudes of practitioners. Considering this research gap, the present study will focus on the attitudes of principals among primary and secondary schools. In addition, while the theme is centred around international education, this research is not restricted to primary and secondary schools that already international school status. As argued by Hayden and Thompson (1995), international education may be experienced by students who have never attended schools that claim to be international; likewise, international schools may provide education that not internationally minded at all.

\section{Methodology}

\subsection{Sampling}

Firstly, after considering certain practical criteria such as accessibility and geographical proximity, I decided to conducted this research in Taiwan. The population of this research is the principals of elementary schools (primary), junior high schools (secondary) and senior high schools (secondary) across three cities of southern Taiwan: Yunlin County, Chiayi City (including Chiayi County) and Tainan City. Then, stratified random sampling of respondents is adopted to ensure a greater level of representativeness and reduce the extent of sampling errors (Gray, 2014). Based on the information provided by the official website of the Educational Bureau, the full name of each school was collected and coded (509 elementary schools; 122 junior high schools; 76 senior high schools), then, Microsoft Excel 2010 was used to generate 3 random number tables for each educational level of school. The first 40 schools from each table were drawn, generating a total of 120 schools. Informed consent forms were sent to principals of the 120 schools, ensuring their rights to decide whether to participate in the research were understood and agreed. After receiving replies, essential details including the full name of the principals and school addresses were gathered from official websites. Then, I administered the inform consent form, questionnaire, recommendation letter and self-addressed stamped envelope by post.

\subsection{Development of Research Instrument}

The questionnaire adopts a five-point Likert scale method for data collection. After completing the first draft of the questionnaire, three experts in the field were included to provide critical appraisal of the instrument. According to Gray (2014), this can demonstrate at least face validity, which ascertains when an instrument appears to assess the intended measures. The breadth and appropriateness of the questionnaire content is examined by two scholars in the field and one practitioner. The questionnaire was then modified based on the suggestions provided by these experts.

The final draft of the questionnaire includes the first section, which deals with individual demographic information (gender and academic degree) and background information of their serving schools (level and type). Gender is divided into male and female; academic degree is classified by Bachelor's, Master's and Doctorates. Level of school includes primary, junior high and senior high; school type is categorised by public and private. The second section investigates the positive effects that international exchange activities can bring to students, while the third looks at negative aspects. The last section deals with the challenges in implementing international exchange activities; the items of this part were collected based on the implementation challenges raised in the White Paper (2012), aiming to identify whether these challenges raised in the document are felt by the principals. Each section is composed of nine items. In addition, all questionnaire items were translated into Chinese by the researcher and checked by a native Chinese person for accuracy. The questionnaire was administered at the end of May 2017, and replies were received three weeks later.

\subsection{Validity}

The construct validity of the questionnaire is further estimated by factor analysis. Considering the unobservable and abstract essence of researched construct of interest (i.e., attitudes towards international exchange activities), a requirement for solid validity is evident. Table 1 represents that the KMO value of section $\mathrm{B}(.831)$ and section $\mathrm{D}(.843)$ are meritorious, while section $\mathrm{C}(.742)$ is acceptable. As for Bartlett's test of Sphericity, each section has achieved statistical significance (.000). These results also indicate that the questionnaire is suitable for further factor analysis. The result of factor analysis for each section is illustrated in Table 2, Table 3 and Table 4 . 
Table 1. KMO and Bartlett's test

\begin{tabular}{llll}
\hline & Section B & Section C & Section D \\
\hline KMO Measure of Sampling Adequacy & .831 & .742 & .843 \\
Bartlett's Test. Approx. Chi-Square & 300.127 & 246.875 & 383.806 \\
Sig. & .000 & .000 & .000 \\
\hline
\end{tabular}

Table 2. Factor analysis results of section B

\begin{tabular}{lllll}
\hline & Item & Factor Loadings & Eigenvalues & \\
\hline B01 & .632 & & \\
B02 & .732 & \\
B03 & .753 & & \\
Section B & B04 & .679 & 4.246 & \\
& B05 & .648 & \\
B06 & .617 & \\
B07 & .706 & \\
B08 & .699 & \\
\hline
\end{tabular}

Table 3. Factor analysis results of section C

\begin{tabular}{lllll}
\hline & Item & Factor Loadings & Eigenvalues & \% of Variance \\
\hline & $\mathrm{C} 01$ & .609 & & \\
& $\mathrm{C} 02$ & .693 & & \\
& $\mathrm{C} 03$ & .487 & & \\
& $\mathrm{C} 04$ & .166 & 3.453 & $38.36 \%$ \\
Section C & $\mathrm{C} 05$ & .462 & & \\
& $\mathrm{C} 06$ & .680 & & \\
& $\mathrm{C} 07$ & .769 & & \\
& $\mathrm{C} 08$ & .729 & & \\
& $\mathrm{C} 09$ & .747 & & \\
\hline
\end{tabular}

Table 4. Factor analysis results of section D

\begin{tabular}{lllll}
\hline & Item & Factor Loadings & Eigenvalues & \% of Variance \\
\hline & D01 & .818 & & \\
& D02 & .794 & & \\
& D03 & .733 & & \\
Section D & D04 & .759 & & \\
& D05 & .680 & 4.655 & \\
& D06 & .590 & & \\
& D07 & .775 & & \\
& D08 & .666 & & \\
& D09 & .623 & & \\
\hline
\end{tabular}

\subsection{Reliability Analysis}

The reliability of the questionnaire is examined by Chronbach's alpha. Regarding the interpretation of Chronbach's alpha, a commonly accepted rule for the resulting alpha coefficient of reliability ranges from 0 to 1 . A reliable questionnaire should have an Alpha coefficient over 0.8 of the whole instrument; and the Alpha coefficient of each section should be higher than 0.7 (George and Mallery, 2003; DeVellis, 2012).

Table 5 demonstrates that Cronbach's Alpha coefficient is .806, which indicates a good extent of internal consistency for the scale with the representative sample. After analysing the reliability of the whole scale, each section was further examined separately. From Table 6, Table 7 and Table 8, Cronbach's Alpha of each section has fulfilled the requirement of at least 0.7. The column 'Cronbach's Alpha if Item Deleted' presents the value that the Alpha coefficient may be if the particular item was deleted from the scale. Table 6 and Table 8 show that no items in Cronbach's Alpha in this column were higher than that of their respective section, indicating that no 
items should be removed. While for Table 7, Cronbach's Alpha (.804) of item C04 in this column was higher than that of section C (.773). However, according to Goforth (2015), Cronbach's Alpha simply provides an overall reliability coefficient for a set of items. Therefore, theoretical and substantive knowledge should also be considered to decide whether an item should be discarded. Given that item C04 ("excessive pressure may impair students' willingness of learning") was induced from previous literature regarding negative effects of international education on students (Wu, Garza and Guzman, 2015) and was a highly probable negative effect in a logical sense, this item was retained.

Table 5. Reliability statistics of the whole questionnaire

\begin{tabular}{|c|c|c|c|}
\hline Cronbach's Alpha & $\begin{array}{c}\text { Cronbach's Alpha } \\
\text { on Standardised Items }\end{array}$ & Based & $\mathrm{N}$ of Items \\
\hline .806 & .795 & & 27 \\
\hline
\end{tabular}

Table 6. Reliability statistics of section B

\begin{tabular}{lll}
\hline Questions & Cronbach's Alpha if Item Deleted & Cronbach's Alpha of section B \\
\hline B01 & .848 & \\
B02 & .836 & \\
B03 & .834 & \\
B04 & .842 & .857 \\
B05 & .846 & \\
B06 & .850 & \\
B07 & .839 & \\
B08 & .841 & \\
B09 & .841 & \\
\hline
\end{tabular}

Table 7. Reliability statistics of section C

\begin{tabular}{lll}
\hline Questions & Cronbach's Alpha if Item Deleted & Cronbach's Alpha of section C \\
\hline C01 02 & .750 & \\
C0 & .737 & \\
C04 & .766 & .773 \\
C05 & .804 & \\
C06 & .770 & \\
C07 & .734 & \\
C08 & .723 & \\
C09 & .733 & \\
\hline
\end{tabular}

Table 8. Reliability Statistics of Section D

\begin{tabular}{lll}
\hline Questions & Cronbach's Alpha if Item Deleted & Cronbach's Alpha of section D \\
\hline D01 & .856 & \\
D02 & .859 & \\
D03 & .865 & \\
D04 & .862 & .879 \\
D05 & .870 & \\
D06 & .876 & \\
D07 & .859 & \\
D08 & .871 & \\
D09 & .873 & \\
\hline
\end{tabular}

To conclude, the reliability analysis demonstrates that the instrument used in my research has satisfactory internal consistency and thus proves to be reliable.

\subsection{Statistical Analysis}

The quantitative data collected from the questionnaire was manually imputed into Microsoft Excel 2010. This was in a 'flat-file' format with each respondent assigned a numerical value ranging from 1-120. Each returning 
questionnaire was coded to identify individual respondent answers and to help check data omissions or errors. The variables of section A were assigned a value for category data; values from 1 to 5 represent the level of agreement (strongly disagree, disagree, neutral, agree, strongly agree) for section $\mathrm{B}$, section $\mathrm{C}$ and section $\mathrm{D}$. The error check for whether the total variables match the number of respondents was also completed. The keyed data was analysed using Statistical Product and Service Solutions (SPSS) 22.0. The statistical approach is illustrated below:

1). Descriptive Statistics

The demographic background information is presented by frequency, percentage of respondent category, mean and Standard Deviation to identify data distribution.

\section{2). Independent Sample T-Test}

The independent sample T-Test was adopted to assess statistical significance of the answers by gender (male and female), and type of school (public or private).

\section{3). One Way ANOVA}

Statistical significance by academic degree (Bachelor, Master and Doctorate) and level of school (elementary school, junior high school and senior high school) were examined by one-way ANOVA. Below (Figure 2.) is the structure for data analysis

\begin{tabular}{|c|c|c|}
\hline Demographic Information & $T$ test & \multirow[b]{2}{*}{ Levels of Agreement } \\
\hline \multirow{2}{*}{$\begin{array}{l}\text { 1. Gender } \\
\text { 2. Type of school }\end{array}$} & \multirow[t]{3}{*}{ Descriptive statistics } & \\
\hline & & $\begin{array}{l}\text { 1. Positive effects of international education } \\
\text { 2. Negative effects of international }\end{array}$ \\
\hline \multirow[b]{2}{*}{$\begin{array}{l}\text { Demographic Information } \\
\text { 3. Academic Degree } \\
\text { 4. Level of school }\end{array}$} & & education \\
\hline & Descriptive statistics & $\begin{array}{l}\text { 3. Challenges to implement international } \\
\text { education }\end{array}$ \\
\hline
\end{tabular}

Figure 2. Framework of statistical analysis

\subsection{Ethical Issues}

Regarding ethical considerations in the present study, basic ethical principles of research conduction have been complied with following the guidelines of the British Education Research Association (BERA). These include sending informed consent forms, respecting rights to decide whether to respond, and ensuring anonymity and confidentiality for data analysis. Also, the returning questionnaire is stored securely and will be disposed after three years. Another ethical involved is promises and reciprocity (Gray, 2014). Promises were made in the introduction of the questionnaire that the research findings will be reported to the respondents. This ensures that people cooperating with the research can gain the newest information regarding the project. Any suggestions may also ultimately help them to improve policy implementation.

\subsection{Limitations}

The question items were included based on the researcher's decision of what is required to answer the research questions. This may involve a certain degree of researcher imposition and cause some important information to be omitted. Consequently, to ensure errors in the questionnaire are reduced, pre-testing is recommended with follow-up debriefing sessions. However, it is unpractical considering the time constraint of fieldwork. As a consequence, this research adopts three scholars in the field to examine whether there is ambiguity in the words, misinterpretation of questions, or any other problems associated with the questionnaire.

\section{Research Findings}

\subsection{Demographic Backgrounds of the Respondents}

The questionnaire was distributed to 120 principals in Taiwan, of which, 89 were retrieved and resulted in a return rate of approximately $74 \%$. The breakdown of these respondents includes: 69 (77.5\%) male and 20 (22.5\%) female; $80.9 \%$ respondents have a Master's degree, which occupies the highest proportion. This is 
followed by Doctorate $(10.1 \%)$ and Bachelor degrees $(9 \%)$. Distribution by level of school is as follows: elementary schools (39.3\%), junior high schools (38.2\%) and senior high schools $(22.5 \%)$. Over half of the respondents $(89.9 \%)$ serve in public schools while only one tenth $(10.1 \%)$ in private schools.

\subsection{Descriptive Analysis of Each Question Item}

Due to the different nature of the question items in each section, every item is analysed individually. The mean of each item in section B (positive effects of international exchange activities) is presented in Table 4-1. Every item has a mean over 4 , indicating that the benefits of international exchange activities are generally recognised by all participating principals. Agreement is strongest in item B08 'Respecting and appreciating different cultures' (4.46) and item B01 'Enhancing intercultural communication skills' (4.36). However, for item B03 'Increasing opportunities for transnational employment' (3.88), the value is between 'neutral' to 'agree'. Possible reasons for this result may be the uncertainty among the principals whether international exchange activities can influence on future careers, as entering the workforce may not be a current concern of students at these ages.

Table 9. Mean of each item in section B (positive effects)

\begin{tabular}{llll}
\hline Section & Item & Mean & Std. Deviation \\
\hline \multirow{6}{*}{} & B01 & 4.36 & .69 \\
& B02 & 4.27 & .64 \\
& B03 & 3.88 & .77 \\
B & B04 & 4.21 & .61 \\
& B05 & 4.13 & .71 \\
& B06 & 4.03 & .75 \\
& B07 & 4.16 & .71 \\
& B08 & 4.46 & .60 \\
& B09 & 4.22 & .62 \\
\hline
\end{tabular}

Results on a set of items asked of the respondents regarding perceived negative effects of international exchange activities are presented in Table 10. Based on these findings, it appears that respondents are generally not in agreement with the statements. However, item C04 'Excessive pressure may impair students' will of learning' (4.02) is the exception, which received the most agreement. This may probably due to the existing examination-oriented education system in Taiwan. Students have been placed under excessive pressure that they are likely to be overwhelmed by extra pressure from international exchange activities. In addition, item $\mathrm{C} 05$ 'Instructors' subjective international outlook may cause misleading international cognition' (3.48) and item C06 'International activities focusing on a small number of powerful countries may cause narrowed international outlook' (3.20) also receive high agreement.

Table 10. Mean of each item of section C (negative)

\begin{tabular}{llll}
\hline Section & Item & Mean & Std. Deviation \\
\hline \multirow{6}{*}{} & C01 & 2.34 & .75 \\
& C02 & 2.70 & .90 \\
& C03 & 2.55 & .92 \\
$\mathrm{C}$ & $\mathrm{C} 04$ & 4.02 & .64 \\
& $\mathrm{C} 05$ & 3.48 & .93 \\
& $\mathrm{C} 06$ & 3.20 & .93 \\
& $\mathrm{C} 07$ & 3.10 & .97 \\
& $\mathrm{C} 08$ & 2.24 & 1.08 \\
& $\mathrm{C} 09$ & 2.52 & .92 \\
\hline
\end{tabular}

Results of attitudes towards the issues regarding implementation challenges are presented in Table 11. A key finding emerged whereby respondents maintain a stance of neutrality towards most of the statements in this section. Nevertheless, item D05 'Lack of consistent funding from the authorities' (4.44) and item D06 'Students with inferior social background usually cannot afford to participate international exchange activities' (4.27) received a higher extent of agreement. Possible explanations to this might be the fact that monetary factors are 
widely considered fundamental when organising an event or activity. This may account for the high scores placed on these two money-related issues. In addition, principals were also inclined to agree on the item D07 'lack of qualified teaching staff and administrators for international exchange activities' (3.94). The most probable reason may be associated with the content of teacher training courses in Taiwan. As 'international education' has not been included in the subjects of the courses, a large proportion of practicing teachers have not received training for international education. Besides, it is interesting to note that a high standard deviation exists in D08 'Lack of mutual cooperation among school staff' (1.05). This may due to differences of institutional culture, which will be explored further in the Discussion.

Table 11. Mean of each item of section D (implementation challenges)

\begin{tabular}{llll}
\hline Section & item & Mean & Std. Deviation \\
\hline \multirow{6}{*}{ D01 } & 3.38 & .85 \\
& D02 & 3.46 & .91 \\
& D03 & 3.26 & 1.03 \\
& D04 & 3.52 & .91 \\
& D05 & 4.44 & .69 \\
& D06 & 4.27 & .84 \\
& D07 & 3.94 & .87 \\
& D08 & 3.31 & 1.05 \\
& D09 & 3.58 & .85 \\
\hline
\end{tabular}

\subsection{Results of Independent T-Tests}

A series of independent t-tests were conducted to examine levels of statistical differences between mean scores. Firstly, whether attitudes towards 'positive effects, negative effects and implementation challenges' of international exchange activities differ significantly between genders is assessed. The result indicates that the score of each item in section $\mathrm{B}$, section $\mathrm{C}$ and section $\mathrm{D}$ has not achieved significance level $(\mathrm{p}<.05)$ by gender. This reveals similar attitudes between male and female principals in all parts of the questionnaire. Afterwards, an independent t-test was conducted again to determine statistical differences between types of school. The results reveal that there is no statistical difference among the attitudes, irrespective of public or private schools.

In terms of perceived negative effects, Table 12 indicates that attitudes towards item C01 'Culture shock may cause unsatisfactory learning outcome' has statistical significance $(\mathrm{p}=.03<.05)$ by type of school. The results show that agreement among principals of private schools is significantly higher than that of public schools.

Table 12. Independent t-test between type of school (negative effects)

\begin{tabular}{|c|c|c|c|c|c|}
\hline Type & & Mean & Std. Deviation & $\mathrm{t}$ & $\mathrm{p}$ \\
\hline & public & 2.29 & .73 & -1.90 & .03 \\
\hline & private & 2.78 & .83 & & \\
\hline \multirow[t]{2}{*}{$\mathrm{C} 02$} & public & 2.69 & .87 & -.29 & .39 \\
\hline & private & 2.78 & 1.20 & & \\
\hline \multirow[t]{2}{*}{$\mathrm{C} 03$} & public & 2.56 & .90 & .36 & .36 \\
\hline & private & 2.44 & 1.13 & & \\
\hline \multirow[t]{2}{*}{$\mathrm{C} 04$} & public & 4.04 & .65 & .66 & .26 \\
\hline & private & 3.89 & .60 & & \\
\hline \multirow[t]{2}{*}{$\mathrm{C} 05$} & public & 3.49 & .93 & .13 & .45 \\
\hline & private & 3.44 & 1.01 & & \\
\hline \multirow[t]{2}{*}{$\mathrm{C} 06$} & public & 3.20 & .93 & -.07 & .48 \\
\hline & private & 3.22 & .97 & & \\
\hline \multirow[t]{2}{*}{$\mathrm{C} 07$} & public & 3.08 & .96 & -.76 & .23 \\
\hline & private & 3.33 & 1.00 & & \\
\hline \multirow[t]{2}{*}{$\mathrm{C} 08$} & public & 2.18 & 1.02 & -1.2 & .14 \\
\hline & private & 2.78 & 1.48 & & \\
\hline \multirow[t]{2}{*}{$\mathrm{C} 09$} & public & 2.46 & .87 & -1.3 & .12 \\
\hline & private & 3.00 & 1.22 & & \\
\hline
\end{tabular}




\subsection{Results of One-Way ANOVA}

One-way ANOVA is conducted to determine whether there are statistically significant differences (at the 0.05 level) among the mean scores of different educational backgrounds. An analysis of variance shows that attitudes towards item B03 'Increasing opportunities for transnational employment' are significantly different, F $(2,87)=$ $5.40, p=.01$. Post hoc analysis using the Scheffé's post hoc criterion for significance indicates that the average scores are significantly higher in principals with Master's degrees $(\mathrm{M}=4, \mathrm{SD}=0.69)$ than in those with Doctorate degrees $(\mathrm{M}=3.33, \mathrm{SD}=1.12)$. Besides, significant differences are seen in item B05 'Cultivating cultural adaptability in the workplace' $(\mathrm{p}=.02)$, item B06 'Developing national identity' $(\mathrm{p}=.02)$ and item B09 'Deepening foreigners' understanding of Taiwanese culture' $(\mathrm{p}=.01)$. Post hoc analysis suggests that, for these three items, the average scores are all significantly higher in teachers with a Master's degree than for principals with a Bachelor's degrees. Results appear in Table 4-5.

Table 13. ANOVA of educational background (positive effects)

\begin{tabular}{|c|c|c|c|c|c|c|}
\hline Item & Level & Mean & Std. Deviation & $\mathrm{F}$ & Sig. & $\begin{array}{l}\text { Post Hoc } \\
\text { Tests }\end{array}$ \\
\hline & (1) Bachelor & 4.13 & .64 & & & \\
\hline \multirow[t]{3}{*}{ B01 } & (2) Master & 4.39 & .68 & .521 & .59 & NS \\
\hline & (3) Doctorates & 4.33 & .87 & & & \\
\hline & (1) Bachelor & 4.00 & .53 & & & \\
\hline \multirow[t]{3}{*}{ B02 } & (2) Master & 4.33 & .63 & 1.93 & .15 & NS \\
\hline & (3) Doctorates & 4.00 & .71 & & & \\
\hline & (1) Bachelor & 3.38 & .52 & & & \\
\hline \multirow[t]{3}{*}{ B03 } & (2) Master & 4.00 & .69 & 5.40 & .01 & (2) $>$ (3) \\
\hline & (3) Doctorates & 3.33 & 1.12 & & & \\
\hline & (1) Bachelor & 3.88 & .64 & & & \\
\hline \multirow[t]{3}{*}{ B04 } & (2) Master & 4.26 & .58 & 1.62 & .21 & NS \\
\hline & (3) Doctorates & 4.11 & .78 & & & \\
\hline & (1) Bachelor & 3.50 & .53 & & & \\
\hline \multirow[t]{3}{*}{ B05 } & (2) Master & 4.22 & .65 & 4.19 & .02 & (2) $>(1)$ \\
\hline & (3) Doctorates & 4.00 & 1.00 & & & \\
\hline & (1) Bachelor & 3.38 & .74 & & & \\
\hline \multirow[t]{3}{*}{ B06 } & (2) Master & 4.13 & .75 & 4.10 & .02 & $(2)>(1)$ \\
\hline & (3) Doctorates & 3.89 & .33 & & & \\
\hline & (1) Bachelor & 3.75 & .89 & & & \\
\hline \multirow[t]{3}{*}{ B07 } & (2) Master & 4.25 & .67 & 3.44 & .04 & NS \\
\hline & (3) Doctorates & 3.78 & .67 & & & \\
\hline & (1) Bachelor & 4.00 & .76 & & & \\
\hline \multirow[t]{3}{*}{ B08 } & (2) Master & 4.54 & .56 & 3.92 & .02 & NS \\
\hline & (3) Doctorates & 4.22 & .67 & & & \\
\hline & (1) Bachelor & 3.88 & .35 & & & \\
\hline \multirow[t]{2}{*}{ B09 } & (2) Master & 4.32 & .60 & 4.89 & .01 & $(2)>(1)$ \\
\hline & (3) Doctorates & 3.78 & .67 & & & \\
\hline
\end{tabular}

One-way analysis of variance is repeated to detect significant differences among responses of principals from elementary, junior and senior high school. Table 13 reveals that attitudes towards item B01 'Enhancing intercultural communication skills' are significantly different, $\mathrm{F}(2,87)=4.52, \mathrm{p}=.01$. Scheffé's post hoc criterion for significance indicates that the average scores are significantly higher in principals from senior high schools $(\mathrm{M}=4.75, \mathrm{SD}=.55)$ than in principals from junior high schools $(\mathrm{M}=4.21, \mathrm{SD}=.73)$. This may result from an international-related policy implemented in senior high schools, which will be detailed in the discussion chapter. For item B03 'Increasing opportunities for transnational employment', attitudes are also of significant difference, $\mathrm{F}(2,87)=5.53, \mathrm{p}=.01$. Post hoc results show that the average scores were significantly higher in elementary school principals $(\mathrm{M}=3.59, \mathrm{SD}=.70)$ than in junior high school principals $(\mathrm{M}=3.85, \mathrm{SD}=.93)$. It is interesting to note that this item has the lowest mean in section B, while has significance differences in the responses. 
Table 13. ANOVA level of school (positive effects)

\begin{tabular}{|c|c|c|c|c|c|c|}
\hline Item & Level & Mean & Std. Deviation & $\mathrm{F}$ & Sig. & $\begin{array}{l}\text { Post Hoc } \\
\text { Tests }\end{array}$ \\
\hline \multirow{3}{*}{ B01 } & (1) elementary & 4.29 & .67 & & & \\
\hline & (2) junior & 4.21 & .73 & 4.52 & .01 & $(3)>(2)$ \\
\hline & (3) senior & 4.75 & .55 & & & \\
\hline \multirow{3}{*}{ B02 } & (1) elementary & 4.40 & .65 & & & \\
\hline & (2) junior & 4.06 & .55 & 3.18 & .05 & NS \\
\hline & (3) senior & 4.40 & .68 & & & \\
\hline \multirow{3}{*}{ B03 } & (1) elementary & 4.17 & .62 & & & \\
\hline & (2) junior & 3.59 & .70 & 5.53 & .01 & $(1)>(2)$ \\
\hline & (3) senior & 3.85 & .93 & & & \\
\hline \multirow{3}{*}{ B04 } & (1) elementary & 4.17 & .62 & & & \\
\hline & (2) junior & 4.12 & .54 & 2.04 & .14 & NS \\
\hline & (3) senior & 4.45 & .69 & & & \\
\hline \multirow{3}{*}{ B05 } & (1) elementary & 4.29 & .67 & & & \\
\hline & (2) junior & 4.06 & .65 & 1.36 & .26 & NS \\
\hline & (3) senior & 4.00 & .86 & & & \\
\hline \multirow{3}{*}{ B06 } & (1) elementary & 4.14 & .69 & & & \\
\hline & (2) junior & 3.85 & .82 & 1.64 & .20 & NS \\
\hline & (3) senior & 4.15 & .67 & & & \\
\hline \multirow{3}{*}{ B07 } & (1) elementary & 4.31 & .68 & & & \\
\hline & (2) junior & 3.91 & .71 & 3.53 & .03 & NS \\
\hline & (3) senior & 4.30 & .66 & & & \\
\hline \multirow{3}{*}{ B08 } & (1) elementary & 4.51 & .61 & & & \\
\hline & (2) junior & 4.35 & .65 & .90 & .41 & NS \\
\hline & (3) senior & 4.55 & .51 & & & \\
\hline \multirow{3}{*}{ B09 } & (1) elementary & 4.31 & .53 & & & \\
\hline & (2) junior & 4.15 & .56 & .65 & .53 & NS \\
\hline & (3) senior & 4.20 & .83 & & & \\
\hline
\end{tabular}

Regarding the implementation challenges, attitudes towards item D07 'Lack of qualified teaching staff and administrators for international exchange activities' reached significant difference, F $(2,87)=4.53, \mathrm{p}=.01$. Post hoc results show that the average scores are significantly higher for elementary school principals $(\mathrm{M}=4.06, \mathrm{SD}$ $=.84)$ than for senior high school principals $(\mathrm{M}=3.45, \mathrm{SD}=.83)$. In addition, the average scores are also significantly higher for junior high school principals $(\mathrm{M}=4.12, \mathrm{SD}=.84)$ than in senior high school principals $(\mathrm{M}=3.45, \mathrm{SD}=.83)$. This reveals a tendency that principals in schools of higher educational stage agreed less on the lack of qualified teaching staff and administrators for the activities.

Likewise, attitudes towards item D08 'Lack of mutual cooperation among school staff' reached significant difference, $\mathrm{F}(2,87)=8.01, \mathrm{p}=.00$. Post hoc results show that the average scores are significantly higher for elementary school principals $(\mathrm{M}=3.49, \mathrm{SD}=.92)$ than for senior high school principals $(\mathrm{M}=2.55, \mathrm{SD}=1.05)$. Average scores are also significantly higher for junior high school principals $(\mathrm{M}=3.59, \mathrm{SD}=.99)$ than senior high school principals $(\mathrm{M}=2.55, \mathrm{SD}=1.05)$. This indicates a situation that disengagement among faculty members is more urgent in schools of lower educational levels. The findings are presented in Table 14. 
Table 14. ANOVA level of school (implementation challenges)

\begin{tabular}{|c|c|c|c|c|c|c|}
\hline Item & Level & Mean & Std. Deviation & $\mathrm{F}$ & Sig. & $\begin{array}{l}\text { Post Hoc } \\
\text { Tests }\end{array}$ \\
\hline \multirow{3}{*}{ D01 } & (1) elementary & 3.51 & .74 & & & \\
\hline & (2) junior & 3.41 & .74 & 1.58 & .21 & NS \\
\hline & (3) senior & 3.10 & 1.12 & & & \\
\hline \multirow{3}{*}{ D02 } & (1) elementary & 3.49 & .66 & & & \\
\hline & (2) junior & 3.56 & .93 & .75 & .48 & NS \\
\hline & (3) senior & 3.25 & 1.21 & & & \\
\hline \multirow{3}{*}{ D03 } & (1) elementary & 3.26 & 1.04 & & & \\
\hline & (2) junior & 3.38 & 1.02 & .65 & .52 & NS \\
\hline & (3) senior & 3.05 & 1.05 & & & \\
\hline \multirow{3}{*}{ D04 } & (1) elementary & 3.54 & .85 & & & \\
\hline & (2) junior & 3.62 & .89 & .79 & .46 & NS \\
\hline & (3) senior & 3.30 & 1.03 & & & \\
\hline \multirow{3}{*}{ D05 } & (1) elementary & 4.40 & .74 & & & \\
\hline & (2) junior & 4.50 & .56 & .22 & .81 & NS \\
\hline & (3) senior & 4.40 & .82 & & & \\
\hline \multirow{3}{*}{ D06 } & (1) elementary & 4.34 & .73 & & & \\
\hline & (2) junior & 4.35 & .81 & 1.35 & .26 & NS \\
\hline & (3) senior & 4.00 & 1.03 & & & \\
\hline \multirow{3}{*}{ D07 } & (1) elementary & 4.06 & .84 & & & $(1)>(3)$ \\
\hline & (2) junior & 4.12 & .84 & 4.53 & .01 & $(2)>(3)$ \\
\hline & (3) senior & 3.45 & .83 & & & \\
\hline \multirow{3}{*}{ D08 } & (1) elementary & 3.49 & .92 & & & (1) $>$ (3) \\
\hline & (2) junior & 3.59 & .99 & 8.01 & .00 & (2) $>$ (3) \\
\hline & (3) senior & 2.55 & 1.05 & & & \\
\hline \multirow{3}{*}{ D09 } & (1) elementary & 3.60 & .85 & & & \\
\hline & (2) junior & 3.71 & .87 & 1.12 & .33 & NS \\
\hline & (3) senior & 3.35 & .81 & & & \\
\hline
\end{tabular}

\section{Discussion}

5.1 What Are the Attitudes of Taiwanese Principals towards the Positive Effects of International Exchange Activities for Students of Primary and Secondary Education?

The most significant finding in this section was arguably that most of the principals held a neutral stance towards the possibility that students' opportunities for transnational employment can increase through participating international exchange activities. This result is different from the finding of a study conducted by Crossman and Clarke (2009). In their interview with employers, academics and students, these three groups of stakeholders possess a strong agreement that the fundamental competencies to enhance transnational employability can be cultivated through experiences of international activities. These competencies, argued by them, are critical analysis ability, sociability and adaptability in the setting with diverse culture. In addition, in the research on the extent to which participation in international programs abroad influences the opportunities of their subsequent employment, Pietro (2015) found that taking programs or exchange activities overseas has a relatively large effects on the chances of being in employment afterward. These perspectives gained from studies of Crossman and Clarke (2009) and Pietro (2015) indicate a slight discrepancy in the agreement from the finding of my research. This discrepancy might due to the fact that the implementation objects are students at primary and secondary education levels. Head-teachers of my study may be uncertain of whether international exchange activities can have a far-reaching impact on the future employment of these young students. However, this finding is contrary to that of a nine-year longitudinal study conducted in South Carolina (2014). A career counselling was brought into its public primary schools in a view to better connecting graduating students to their future career. Students in these schools were asked about their interests and academic preferences. Afterwards, the counsellor met with the student and parents to develop a plan that help clarify which elective course should be taken in high schools to bolster specific interests. The finding revealed that a majority of graduates surveyed years ago agree they had benefited from the counselling as they had already enrolled in courses related to their potential career. This research implies the importance to exposing students to their 
professional career as early as possible, which is not consistent with the attitudes of the head-teachers in the present study.

However, among these items, agreement is strongest in the statement that students can learn to respect and appreciate different cultures, as this found to be the primary goal of international exchange activities. This positive effect is embedded in the purpose of an internationalist international education, which believes that students can be cultivated into citizens with positive attitudes towards the world through the inculcation of core values such as respect and appreciation towards other cultures (James, 2005). In addition, if relating this finding here in my research back to Kurt Hahn's (1950) primary goal of international activities, which has been discussed in the Literature chapter, it is to eliminate national prejudices through gathering diverse-cultural young students to study and work together. From this point, it is evident that the abilities to respect and appreciate another person irrespective of their culture backgrounds, has long been advocated. The general agreement on this effect is also in lines with the previous study of Carley, et al., (2006) which is a survey was conducted to examine a group of faculty members' attitudes towards international learning in Kennesaw State University in America. Of this survey, the results revealed that international education activities enable students to be more appreciative and more concerned about other cultures and affairs.

A further issue that also received broad agreement is that international exchange activities can be an effective way to practice intercultural communication skills. In Taiwan, foreign language classes often focus on the practice of reading and vocabulary memorisation. Thereafter, opportunities for practicing listening and speaking are scarce. This argument is substantiated in Fu's (2013) project that was designed for teachers to help enhance English listening and speaking skills of their $4^{\text {th }}$ graders in Taiwan. Fu (2013) asserts that while communicative language teaching is the main principle that adopted by most of the English curriculums, there is actually a gap between what is claimed to be accomplished and the performance of students' listening and speaking proficiency. She further explains that as English is the most crucial foreign language for college or university application and career development, a curriculum or activities targeting English listening and speaking abilities should be developed. Under this context, as listening and speaking abilities are two components that often considered as the most important parts of communication; this reason may explain why the principals in my research are more likely to believe that international exchange activities can offer ample opportunities for students to communicate with people from other countries. This widely recognised benefit among the principals is consistent with the findings of Hayden, et al. (2003) indicating a general agreement on an enhanced communication ability among students from 72 different nationalities participating six international programs in the UK. Hansen (2002, p.7) supported the abovementioned argument of the obtained abilities of international students in the review of the definition and effects of international education exchange. She asserted that students can become proficient in the language spoken in the host country and thus boosting their confidence with 'a can-do attitude' and a sense of independence. Additionally, the importance of cultivating intercultural communication skills is highlighted by The World-Readiness Standards for Learning Languages (2015, p. 16): "Learners who add another language and culture to their preparation are not only college- and career-ready, but are also "world-ready". This helps explain why international exchange activities help prepare students with the capabilities to interact among diverse groups of people, which received agreement among principals in this research.

Besides, the results in my research indicate that academic backgrounds were found to play a key role in head-teachers' attitudes towards other positive effects of international exchange activities such as increasing opportunities for transnational employment, cultivating cultural adaptability in the workplace, developing national identity and deepening foreigners' understanding of Taiwanese culture. It is inferred that people with higher educational background tend to be more critical towards the benefits that one policy can bring to a society. This inference can be partly supported with the report on perceptions of higher education reform by The Gallup Organisation (2007). The result of one survey question regarding the benefit of private funding to university reveals that participants with only a Master's degree are the most likely to agree with the statement, while respondents at doctoral level have the least confidence that more private funding can help universities to obtain additional earnings. Based on the finding of this report, the grounds for the result of the present research is speculative.

\subsection{What Are the Attitudes of Taiwanese Principals towards the Negative Effects of International Exchange Activities for Students of Primary and Secondary Education?}

A higher agreement among the principals can be witnessed on the risk that international exchange activities may impair students' willingness for learning. This result may be highly associated with the credentialism culture (i.e., excessive reliance on academic degrees in determining employment) that has persistently existed in the education system of Taiwan. Bray (2003) links this situation of Taiwan with the outcome of an 
examination-oriented learning environment. He explains that this learning environment has long been considered a major factor for the emergence of private supplementary tutoring in Taiwan and other East Asian countries. According to Kwok (2004, p. 66), as most of these extra fee-paying tutoring provides pedagogical guidelines for examination preparation or university entrance examinations; thus many parents have paid these tutoring fees for their children in the hope that they can obtain higher levels of education and "climb up the social ladder after graduation". To meet parents' high expectation, many students in Taiwan have already been placed under excessive pressure (Liu, 2012). Consequently, if participating in additional international exchange activities, these students may be overwhelmed by overloaded pressure as they must spend extra time preparing for the activities and adapt to cultures of the host countries. This pressure resulted from staying in foreign countries could be detrimental to students' willingness to learn, as substantiated by a previous research by $\mathrm{Wu}$, et al., (2015). Interviews were adopted to explore the learning obstacles and issues of adjustment of 10 international students in America; most of these international students in America maintain that their willingness of learning has been impaired as excessive pressure from physical, psychological, cultural and social relationship have compounded their existing academic pressure.

Among the other negative effects of international exchange activities, the principals in my study also highly believed that the instructors' subjective international outlook may cause misleading international cognition in students. This result matches the observed in earlier study of Deveney (2007). The data obtained from his survey and focus groups with 29 international school teachers in Thailand reveals that teachers' values may dictate the approach of how information is interpreted and conveyed to students. Deveney (2007) further suggests that teachers may possess misconceptions of international issues which would misguide the students they teach. From this finding, the result emerged from my study can be explained and substantiated.

The final finding regarding the attitudes toward the negative effects of international exchange activities in my research is that the question item 'International activities focusing on a number of powerful countries may cause narrowed international outlook' also received a widely agreement among the principals. This imbalance in the selection of visiting countries has been illustrated by Johnstone and Lee (2016). Adopting Canada as a case study, they examine the governance strategies in the international education policy of Canada. The result reveals that most of the visiting countries for international education or exchange activities are western-dominated. Johnstone and Lee (2016) further argue that this situation has fostered the position of western countries for global dominance and economic expediency. Therefore, if students received this kind of international education, they may ultimately fail to embrace cultures from other countries marginalized in the world.

\subsection{What Are the Attitudes of Taiwanese Principals towards the Challenges to Undertake International Exchange} Activities for Students of Primary and Secondary Education?

Among the implementation challenges raised in my questionnaire, the majority of principals held that a lack of consistent funding from the government exerts the greatest influence on the undertaking of international exchange activities. Besides, 'students with inferior social background usually cannot afford to participate international exchange activities' also received a high agreement. These findings reveal that issues related to money are often key elements for the implementation of a policy. As discussed in Apple's (2002) paper, monetary factors are fundamental when planning an event or activity, especially in these years that numerous affairs in education at all levels are associated with economic problems. In the case of my research, because most of the respondents of this research are principals of public schools (89.9\%), which often rely on funding from the authorities. However, due to financial constraints of the government in recent years in Taiwan (Mok, 2000), funding for international exchange activities has been reduced. Under this condition, the subsidy provided for travelling expenses only covers half the flight ticket fee. Consequently, only those students with a superior economic background can afford extra expenditure on the exchange activities. Students with an inferior financial status are thus deprived of the right to participate in these activities. This finding is consistent with Yemini and Goren (2016) and participant teachers at an international school and a local public school in Israel. One participant made an impressive expression during the interview by claiming that "If an Israeli person is busy struggling to survive, how can he care that the rainforests are being cut down in Brazil?" (p.844). This assertion implies that economic underprivileged students may not be able to afford extra activities regarding international education as it is unrealistic given practical financial concerns. Consequently, as numerous resources are required, international education or even the exchange activities are not for everyone. With reference to the limitations of the two perspectives towards international education reviewed earlier in the Literature chapter, this challenge again manifests Bunnell's (2005) critique of 'internationalist' international education as unrealistic since most students may not have enough money to receive this kind of education. On the other hand, the challenge can also be regarded as an aftermath of 'globalist' international education, which is often used by 
privileged parents to enhance individual competition and personal economic advancement of their children to ensure social and economic reproduction (Ball, 2003). Therefore, international education has become a fee-paying phenomenon, and the focused aspect of this study - international exchange activities, -is no exception. As Cambridge (2003) argues, wealthy parents are often willing to pay for exclusive activities as they are vigorously in pursuit of economic advantages for their children. This phenomenon has been described as drawing a clear line between students who are potential global citizens and 'others' (Yemini and Goren, 2016). Furthermore, this gap between the haves and have-nots has made it difficult to promote international exchange activities for every student.

Another challenge for the implementation of international exchange activities raised by principals in my study is the lack of qualified teaching staff and administrators. The underlying reason may be associated with the subjects of teacher training programmes in Taiwan. As 'international education' has not been included in the content of programmes, a substantial proportion of Taiwanese practice teachers have not received related training (Lin and Gorrell, 2001). According to Hayden et al., (2002), the major influence on students is through their interaction with the teaching faculty and other administrators. Additionally, even the syllabus is designed to cater for international education, it still depends largely on the abilities of the teaching faculty to convey the information to students (Webster, 2010) and assistance from administrators in operations management (Stockard and Lehman, 2004). Consequently, the importance of recruiting groups of teaching faculty and administrators qualified for targeted subjects should not be underestimated (Barrick, 2017). In the case of the present research, the result indicates that most faculty members are not directly qualified for the programmes of international exchange. Indeed, they are often recruited from a background in national standardised teacher training programmes, therefore, they have received scare training concerning the international component of their role. This situation is also discussed in Hayden (2001), who states that science graduates are trained to be science teachers, however, there is no similar group of graduates majoring in international-related subjects to be trained specifically as international teachers. Lovett (2003) adds that contemporary schools are discipline-centred and tend to recruit faculty specialising in a topical field rather than those with broad, overseas experiences. With respect to the context in Taiwan, the discipline-centred recruiting is more evident in senior high schools since students at this stage are striving to prepare for specialised subjects for higher education entrance examinations, thus faculty in senior high schools often possess expertise in different academic subjects (Wang, 2013). Under this circumstance, a lack of qualified school staff for international exchange activities is deemed serious than for the situation in schools of other educational levels. However, it is interesting to note that the finding of ANOVA that represents a contradictory scenario; principals in elementary schools agreed on this challenge significantly more than that of senior high schools. This reflects the findings in the research of Chang and Shen (2011) that exploring the stresses faced by 54 elementary school teachers in Taiwan. As teachers at this educational level have to teach all subjects, for instance, a Chinese teacher is also required to teach Mathematics, Social Science, and other subjects, many elementary school teachers are found exhausted and not specialized enough in certain subject. This situation may help explain the finding in my study that elementary school head-teachers agree more on a lack of qualified school staff for international exchange activities. As elementary school faculty members often take on numerous tasks at the same time; they can hardly specialize in and even concentrate on the affairs related to international exchange activities.

A final finding regarding the implementation challenge is a high standard deviation within the responses of the head-teachers - 'lack of mutual cooperation among faculty'. The underlying reasons for this result may due to the differences across institutional cultures (Bray et al., 2004). As Donald (2007) states, depending on the organisational environment, faculty members can both become contributors and inhibitors, either facilitating or impeding an international education policy. Numerous factors can determine the operation of a school and further impact the extent of willingness of cooperation among the members. Friesen (2012) conducted research following a phenomenological approach to explore the attitudes of five Canadian faculty members in different schools towards involving in the process of internationalisation. The results demonstrate three types of situation where one participant expressed a compatibility of personal values with institutional rationales for internationalising their school; while the other two participants held a compromising attitude towards cooperating with the institution as their personal motivations for international work were, to some extent, divergent from the institutional rationales. However, considering the personal profitability of international activities, they kept engaging in the process. On the other hand, the remaining two participants indicated a strong unwillingness to collaborate. They perceive the quantified assessment of international activities as not only irrelevant to their personal career, but also directly threatening their efforts. In direct reference to these findings from Friesen (2012) with that of my research, these three distinct situations of faculty cooperation assist in explaining the high divergence among responses of the principals. It is concluded that as faculty members may 
possess different perceptions towards international exchange activities, variations are all likely to contribute to the differences of faculty morale and thus lead to different extents of willingness for cooperation.

\subsection{Implications}

From this research of principals' attitudes, several implications can be provided for policy-makers in Taiwan and other practitioners striving towards international exchange activities. The key implications are discussed below.

The findings of principals' attitudes towards the positive and negative effects of international exchange activities can be referenced by Taiwanese policy makers to evaluate the effectiveness of this international education policy. As not every positive effect is widely agreed by the principals; policy-makers can further examine the underlying reasons causing these responses, and thus modify the implementation procedures of the existing policy. On the other hand, the attitudes towards the negative effects of international exchange activities found in this research can also reflect the gap between what is expected by the policy-makers and the actual situation experienced by students. Consequently, this gap can be the motivation for policy-makers to cooperate with school practitioners to deal with the problems brought from international exchange activities to the students.

In addition, as indicated from the findings of the perceived implementation challenges, issues related to financial resources are highly considered as hindrances for conducting international exchange activities. Given the current financial constraints in the governmental funding for education in Taiwan, international education seems to be restricted for financially privileged groups and has led to inequality in the provision of international education. This inequality can be regarded as an imbalance between internationalist and globalist international education. Therefore, it involves the need for policy-makers to debate how to maintain an international outlook in students with limited financial resources. For these concerns, ways to overcome the implementation challenges of international education should be further explored and addressed by government in order to maximise the potential of all students to be benefitted by international education.

\subsection{Future Research}

The area that warrants further investigation is to include other educational stakeholders such as teaching faculty and administrators to compare their perspectives with that of their leaders. Other opinions from scholars can also offer more breadth of belief about the effects of international exchange activities and examine whether a gap exists between academia and practitioners. Additionally, given that part of the research purpose in this research was to explore the effects on students, to allow more practicalities, it would be most helpful to directly examine the attitudes of students. A final suggestion concerns the methodology. Quantitative data can be supplemented with qualitative methods such as focus groups and interviews, to identify common themes that may explain the statistical relationships found in the questionnaire.

\section{References}

A White Paper on International Education for Primary and Secondary Schools. (2012). Taipei: Ministry of Education, Republic of China (Taiwan).

Altbach, P, G., \& Knight, J. (2007). The internationalization of higher education: Motivations and realities. Journal of Studies in International Education, 11(3-4), 290-305. https://doi.org/10.1177/1028315307303542

Apple, M. W. (2002). Are we wasting money on computers in schools? Educational Policy, 18(3), 513-522. https://doi.org/10.1177/0895904804265022

Barrick, C. (2017). Get the right people on the bus, Part 1: Recruiting quality faculty. Department Chair, 27(3), 9-11.

Boysen, G. (2012). Teachers' responses to bias in the classroom: How response type and situational factors affect student perceptions. Journal of Applied Social Psychology, 42(2), 506-534. https://doi.org/10.1111/j.1559-1816.2011.00784.x

Bunnell, T. (2005). Perspectives on international schools and the nature and extent of local community contact. Journal of Research in International Education, 4(1), 43-63. https://doi.org/10.1177/1475240905050290

Cambridge, J. (2003). Identifying the globalist and internationalist missions of international schools. International Schools Journal, 22(2), 54-58. https://doi.org/10.1177/1741143214543201

Carley, S., Cheurprakobkit, S., \& Paracka, D. (2006). Faculty Attitudes towards International Education: A Campus Experience. Journal of Global Initiatives: Policy, Pedagogy, Perspective, 1(1).

Chang, K., \& Shen, C. (2011). Aromatherapy benefits autonomic nervous system regulation for elementary school faculty in Taiwan. Evidence-Based Complementary and Alternative Medicine, 1-7. 
http://dx.doi.org/10.1155/2011/946537

Chen, S. H. (2015). Promoting international education for indigenous elementary schools in Taiwan: School principals' perspectives. Asian Social Science, 11(9), 21-31. http://dx.doi.org/10.5539/ass.v11n9p21

Crossley, M., \& Watson, K. (2003). Comparative and international research in education: Globalisation, context and differences. London: Routledge/Falmer. https://doi.org/10.2304/eerj.2004.3.1.13

Crossman, J, E., \& Clarke, M. (2009). International experience and graduate employability: stakeholder perceptions on the connection. Higher Education: The International Journal of Higher Education and Educational Planning, 59(5), 599-613. https://doi.org/10.1007/s10734-009-9268-z

DeVellis, R. F. (2012). Scale development: Theory and applications. Los Angeles: Sage.

Deveney, B. (2007). How well-prepared do international school teachers believe themselves to be for teaching in culturally diverse classrooms? Journal of Research in International Education, 6(3), 309-332. https://doi.org/10.1177/1475240907083198

Dolby, N., \& A. Rahman. (2008). Research in international education. Review of Educational Research, 78(3), 676-726. https://doi.org/10.3102/0034654308320291

Donald, J. (2007). Internationalisation, diversity and the humanities curriculum: Cosmopolitanism and multiculturalism revisited. Journal of Philosophy of Education, 41(3), 289-308. https://doi.org/10.1111/j.1467-9752.2007.00572.x

Emert, H., Pearson, D., Valeau, E. J., \& Raby, R. L. (2007). Expanding the vision of international education: Collaboration, assessment, and intercultural development. New Directions for Community Colleges, 2007(138), 67-75. https://doi.org/10.1002/cc.283

George, D., \& Mallery, P. (2003). SPSS for Windows step by step: A simple guide and reference 11.0 update (4th ed.). Boston: Allyn \& Bacon.

Goforth, G. (2015). Using and Interpreting Cronbach's Alpha. Research Data Services + Sciences.

Goodings, R. F. \& Lauwerys, J. A. (1964). Education and international life. In J. A. Lauwerys (Ed.), Ideals and ideologies (pp. 110-116). London: Evans Brothers.

Goren, H., \& Yemini, M. (2016). Global citizenship education in context: teacher perceptions at an international school and a local Israeli school. Compare: A Journal of Comparative and International Education, 46(5), 832-853. https://doi.org/10.1080/03057925.2015.1111752

Gray, D. E. (2014). Doing research in the real world. London: SAGE.

Hall, S. (1990). Cultural identity and diasporas. In Rutherford J. (Ed.), Identity: Community, Culture, Difference. London: Lawrence and Wishart.

Hansen, H, M. (2002). Defining international education. New Directions for Higher Education, 117, 5-12. https://doi.org/10.1002/he.41

Hayden, M. (2006). International Education: The Context. In: Introduction to International Education: International Schools and their Communities. London: SAGE, 1-8.

Hayden, M. (2006). Introduction to international education: International schools and their communities. London, UK: Sage.

Hayden, M., \& Thompson, J. (1995). International schools and international education: A relationship reviewed. Oxford Review of Education, 21, 327-345. https://doi.org/10.1080/0305498950210306

Hayden, M., \& Thompson, J. (2000). International education: Flying flags or raising standards? International Schools Journal, 19(2), 48-56.

Hayden, M., \& Thompson, J. (2013) 'International Schools: Antecedents, current issues and metaphors for the future', in Pearce R. (ed.) International Education and Schools: Moving beyond the First 40 Years, Bloomsbury Academic, London.

Hayden, M., Thompson, J., \& Williams, G. (2003). Student Perceptions of International Education Stitle a Comparison by Course of Study Undertaken. Journal of Research in International Education, 2(2), 205-232. https://doi.org/10.1177/14752409030022005

Hill, I. (2001). Early stirrings: the beginnings of the international school movement. International Schools Journal, 10(2), 11-22. 
Hobsbawm, E. (1996). Language, culture and national identity. Social Research, 63(4), 1065-1080.

House, K. (2015). The elephant in the room: A critical examination of the International Baccalaureate Diploma Programme's policy discourse. International and Global Issues for Research, (10), 1-23.

Huang, W. D. (2015). A Critical Analysis of the Applicability of Deardorff's Intercultural Competence Model to International Exchange Activities of Taiwan's Primary Schools within Confucian Culture. Contemporary Educational Research Quarterly, 23(3), 125-167.

Hunter, Bill, White, George P., \& Godbey, Galen C. (2006). What does it mean to be globally competent? Journal of Studies in International Education, 10(3), 267-285. https://doi.org/10.1177/1028315306286930

Husen, T., \& Postlethwaite, T. N. (1985). The International Encyclopedia of Education. Oxford: Pergamon Press.

International School of Geneva. (2015). Our history. Retrieved from Ecole Internationale de Geneve: http://www.ecolint.ch/about-ecolint/our-history

James, K. (2005). International education: The concept, and its relationship to intercultural education. Journal of Research in International Education, 4(3), 313-332. https://doi.org/10.1177/1475240905057812

Johnstone, M., \& Lee, E. (2016). Canada and the Global Rush for International Students: Reifying a Neo-Imperial Order of Western Dominance in the Knowledge Economy Era. Critical Sociology, Critical Sociology, 7(27), 1-16. https://doi.org/10.1177/0896920516654554

Joris, M. (2006). IaH: A quality tool for change and institutional management-mainstream approach to help change in your organization and people, from local to cosmopolitan. Rotterdam: NUFFIC.

Kotz, D. M. (2002). Globalization and neoliberalism. Rethinking Marxism, 14(2), 64-79. https://doi.org/10.1080/089356902101242189

Kreber, C. (2009). Different perspectives on internationalization in higher education. New Directions for Teaching and Learning, (118), 1-14. https://doi.org/10.1002/tl.348

Kwok, P. (2004). Examination-oriented knowledge and value transformation in East Asian cram schools. Asia Pacific Education Review, 5(1), 64-75.

Leach, R. J. (1969). International schools and their role in the field of international education. London: Pergamon Press Ltd.

Lin, H. L., \& Gorrell, J. (2001). Exploratory analysis of pre-service teacher efficacy in Taiwan. Teaching and Teacher Education, 17(5), 623-635. https://doi.org/10.1016/S0742-051X(01)00018-X

Liu, J. (2012). Does cram schooling matter? Who goes to cram schools? Evidence from Taiwan. International Journal of Educational Development, 32(1), 46-52. https://doi.org/10.1016/j.ijedudev.2011.01.014

Mathews, Jay. (2001, July 26). IB Programs at Disadvantage; College Credit Guidelines Favor AP. (FairfaxExtra) (International Baccalaureate, Advanced Placement). The Washington Post, p. T03.Parmenter, L., Lam, C., Seto, F., \& Tomita, Y. (2000). Locating self in the world: elementary school children in Japan, Macua and Hong Kong. Compare, 30(2), 133-144.

Mok, K. (2000). Reflecting globalization effects on local policy: Higher education reform in Taiwan. Journal of Education Policy, 15, 637-660. https://doi.org/10.1080/02680930010000236

Pietro, G. D. (2015). Do study abroad programs enhance the employability of graduates? Education Finance and Policy, 10(2), 223-243. https://doi.org/10.1162/EDFP_a_00159

Qiang, Z. (2003). Internationalization of higher education: Towards a conceptual framework. Policy Futures in Education, 1(2), 248-270. https://doi.org/10.2304/pfie.2003.1.2.5

Roman, L. (2003). Education and the contested meanings of 'Global Citizenship'. Journal of Educational Change, 4(3), 269-293. https://doi.org/10.1023/B:JEDU.0000006164.09544.ac

Stier, J. (2003). Internationalization, ethnic diversity and the acquisition of intercultural competencies. Intercultural Education, 14(1), 77-91. https://doi.org/10.1080/1467598032000044674

Stockard, J., \& Lehman, M. B. (2004). Influences on the satisfaction and retention of 1st-Year teachers: The importance of effective school arrangement. Educational Administration Quarterly, 40(5), 742-771. https://doi.org/10.1177/0013161X04268844

Sung, Y., Park, M., \& Choi, Il. (2003). National construction of global education: a critical review of the national curriculum standards for South Korean global high school. Asia Pacific Education, 14, 285-294. 
https://doi.org/10.1007/s12564-013-9256-y

Sylvester, R. (2002). Mapping international education: a historical survey. Journal of Research in International Education, 1(1), 90-125. https://doi.org/10.1177/147524090211005

Thomas, D., \& Inkson, K. (2004). Cultural intelligence. People skills for global business. San Francisco: Berrett-Koehler Publishers.

Umar, M. (2013). Demystifying international education: Concepts, ideas and ideologies. The Maldives National Journal of Research, 1(1), 57-71.

Volet, S., \& Ang, G. (2012). Culturally mixed groups on international campuses: An opportunity for inter-cultural learning. Higher Education Research \& Development, 31(1), 21-37. https://doi.org/10.1080/07294360.2012.642838

Wang, Y. H., \& Chen, C. M. (2013). GIS Education in Taiwanese Senior High Schools: A National Survey Among Geography Teachers. Journal of Geography, 112(2), 75-84. https://doi.org/10.1080/00221341.2011.637227

Watson, D. (1999). 'Loss of face' in Australian classrooms. Teaching in Higher Education, 4(3), 355-362. https://doi.org/10.1080/1356251990040304

Webster, C. (2010). Increasing student motivation through teacher communication. Journal of Physical Education, Recreation \& Dance, 81(2), 29-39. https://doi.org/10.1080/07303084.2010.10598431

Wright, E., Lee, M., Tang, H., \& C, Gordon. (2016). Why Offer the International Baccalaureate Middle Years Programme? A Comparison between Schools in Asia-Pacific and Other Regions. Journal of Research in International Education, 15(1), 3-17. https://doi.org/10.1177/1475240916635896

Wu, H. P., Garza, E., \& Guzman, N. (2015). International students' challenge and adjustment to college. Education Research International, 9. http://dx.doi.org/10.1155/2015/202753

Wylie, M. (2008). Internationalizing curriculum: Framing theory and practice in international schools. Journal of Research in International Education 7(1), 5-19. https://doi.org/10.1177/1475240907086885

Yang, R. (2002). University internationalization: its meanings, rationales and implications. Intercultural Education, 13(1), 81-96. https://doi.org/10.1080/14675980120112968

Young, J. M., (2010). Problems with global education: conceptual contradictions. The Alberta Journal of Educational Research, 56(2), 143-156.

\section{Copyrights}

Copyright for this article is retained by the author(s), with first publication rights granted to the journal.

This is an open-access article distributed under the terms and conditions of the Creative Commons Attribution license (http://creativecommons.org/licenses/by/4.0/). 